UNIVERSIDAD Y TRANSFORMACIONES DE LA SOCIEDAD DE LA INFORMACIÓN EN CHILE. OPINIONES DEL PROFESORADO Y ALUMNADO DE INSTITUCIONES PRIVADAS ACREDITADAS Y NO ACREDITADAS

UNIVERSITY AND TRANSFORMATIONS OF THE INFORMATION SOCIETY IN CHILE. OPINIONS OF TEACHERS AND STUDENTS IN PRIVATE INSTITUTIONS ACCREDITED AND NON ACCREDITED

\section{Volumen 12, Número 2}

Mayo-Agosto

pp. 1-35

Este número se publicó el 30 de mayo de 2012

Emilio Torres Rojas

Revista indizada en REDALYC

Revista distribuida en las bases de datos:

CATÁLOGO DE LATINDEX, IRESIE, CLASE, DIALNET, DOAJ, E-REVIST@S,

Revista registrada en los directorios:

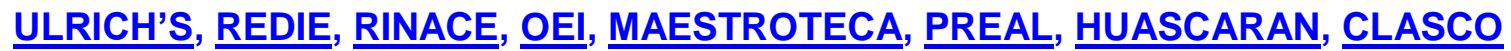




\title{
UNIVERSIDAD Y TRANSFORMACIONES DE LA SOCIEDAD DE LA INFORMACIÓN EN CHILE. OPINIONES DEL PROFESORADO Y ALUMNADO DE INSTITUCIONES PRIVADAS ACREDITADAS Y NO ACREDITADAS
}

UNIVERSITY AND TRANSFORMATIONS OF THE INFORMATION SOCIETY IN CHILE. OPINIONS OF TEACHERS AND STUDENTS IN PRIVATE INSTITUTIONS ACCREDITED AND NON ACCREDITED

\section{Emilio Torres Rojas ${ }^{1}$}

Resumen: Las universidades han cambiado junto con la historia. La globalización, la economía de mercado, la sociedad de la información y los procesos de acreditación y aseguramiento de la calidad han significado cambios profundos en las operaciones del sistema universitario. En Latinoamérica se advierte un impacto aún difuso de estas transformaciones sobre otros procesos universitarios, como la enseñanza-aprendizaje, la innovación en planes de estudio, la creación de carreras, la formación de redes, la administración y los procesos de acreditación institucional. El artículo caracteriza las opiniones que sustenta el profesorado y alumnado sobre la sociedad de la información en Santiago de Chile, mediante una encuesta representativa aplicada a universidades acreditadas y no acreditadas.

Palabras clave: SOCIEDAD DE LA INFORMACIÓN, UNIVERSIDAD PRIVADA, ALUMNADOPROFESORADO, ACREDITACIÓN

\begin{abstract}
Universities have changed along with history. Globalization, market economy, information society and the processes of accreditation and quality assurance have meant profound changes in the operations of the university system. In Latin America, warns a diffuse impact of these changes have on other academic processes, such as teaching and learning, innovation in curriculum, career building, networking, management and institutional accreditation processes. This article discusses the views that supported the teachers and students on the Information Society in Santiago of Chile, by a representative survey applied to accredited and non-accredited universities.
\end{abstract}

Key words: INFORMATION SOCIETY, PRIVATE UNIVERSITY, STUDENTS, TEACHERS, ACCREDITATION

\footnotetext{
Doctor en Psicología y Educación, Universidad de Granada, Sociólogo y Magister en Ciencias Sociales, Universidad de Chile. Académico Escuela de Sociología Universidad Central de Chile.
}

Dirección electrónica: etorres@ucentral.cl

Artículo recibido: 3 de octubre, 2011

Aprobado: 17 de mayo, 2012 


\section{El Problema de Investigación}

Desde sus inicios, la actividad universitaria respondió a los desafíos que cada época le imponía a quienes en ellas se desempeñaban y procuraban atesorar, multiplicar y adquirir el conocimiento acumulado, convencidos de un conjunto de premisas incuestionables que orientaban la labor académica. Hoy, en medio de un radical cambio de era que ha transformado la sociedad, la economía, la cultura y el comportamiento de millones de personas a nivel planetario, aquellos lineamientos tan arraigados en los claustros universitarios, ya no parecen tan firmes y las acciones de quienes las dirigen, el desempeño del cuerpo académico y las formas de aprendizaje de las nuevas generaciones, de la mano de las TIC, ha revolucionado como nunca antes la experiencia educativa. La llamada Sociedad de la Información (en adelante S.I.), en el marco de los procesos de globalización y de un sistema de libre mercado, generó una estructura productiva que demanda nuevas competencias laborales en un medio altamente tecnificado y exigente.

Este problema colinda con el debate intelectual en torno a la "crisis del trabajo", como consecuencia del paso de la sociedad industrial a la sociedad de la información. Ello implica, a su vez, que se han transformado las competencias requeridas para obtener un empleo, especialmente en el sentido de la preparación que hoy demanda la revolución tecnológica. En medio de este estado de cosas, una constatación bastante generalizada entre los entendidos en educación superior se refiere a los serios problemas de funcionamiento interno, eficacia y control de procesos y la escasa sintonía que poseen con el entorno los distintos modelos de universidad. Las universidades arrastraban en muchos casos características tradicionales, que resultan altamente contrastantes respecto del conjunto de transformaciones acontecidas durante las últimas décadas en todo el mundo $\mathrm{y}$, subsecuentemente, poseen escasa capacidad de acoplamiento con los urgentes nuevos imperativos de integración, comparabilidad, convergencia internacional y rendición de cuentas respecto de la utilización eficaz de los fondos públicos entregados (Mora, 2005).

En el caso latinoamericano, la acumulación de estudios de base empírica, aunque se incrementan paulatinamente, aún resultan insuficientes para marcar las tendencias predominantes, tanto en las perspectivas de los actores directamente involucrados, como en los patrones de reacción observados por parte de las universidades que se están sometiendo a los sistemas de acreditación, los cuales no poseen más de diez años de implementación. A esta discusión en la región se agregan problemas y desafíos no resueltos, como la equidad, 
accesibilidad, financiamiento, relevancia social del sistema universitario y el subdesarrollo de los países de la región.

El particular modo en que las transformaciones sociales han influido en el sistema universitario y las formas en que cada institución en el marco de su propia autonomía reacciona ante la S.I., plantea interrogantes insuficientemente indagadas en la región. ¿Cuáles son las adaptaciones del sector privado ante las exigencias que plantea la S.I.?, ¿Se reflejan estos cambios en procesos centrales que desarrollan las universidades tales gestión institucional, enseñanza-aprendizaje, creación de nuevas carreras, administración, etc.?, ¿Qué significados, relaciones y opiniones atribuyen los diversos estamentos universitarios a estas transformaciones en el marco de su propia cotidianeidad?, ¿Cómo se diferencian estos significados y opiniones entre el profesorado y el alumnado?.

La necesidad de repuestas so particularmente cruciales en el sector privado de la educación superior, respecto del cual existe un menor grado de conocimiento acumulado en el país. Este sector educativo posee ya 36 universidades instituidas desde comienzos de la década de los ochenta en Chile y evidentemente el fenómeno no puede considerarse nuevo; sin embargo, se le suele tratar como un ámbito homogéneo, cuando en la realidad posee distintos orígenes, misiones institucionales, tamaños, complejidad y formas de gobierno diversos (Fernández, 2009).

\subsection{Objetivos de la Investigación}

El objetivo general de la investigación consistió en describir los significados y opiniones que expresa el profesorado y alumnado respecto del despliegue de la sociedad de la información, en un conjunto de universidades privadas de la Región Metropolitana de Santiago de Chile.

\section{Objetivos Específicos}

Comparar los significados que los principales estamentos poseen respecto de los cambios universitarios vinculados con la S.I.

a) Describir las opiniones del profesorado y estudiantado respecto del avance de la sociedad de la información en el país y en los procesos centrales de las respectivas universidades. 
b) Detectar los aspectos que los profesores y estudiantes constituyen los principales obstáculos y los aspectos que han favorecido las transformaciones del quehacer universitario.

c) Discutir los alcances de los resultados a la luz de los antecedentes conceptuales y de las particularidades de las universidades estudiadas.

\section{Aspectos teóricos}

\subsection{Era de la información y Nuevos Escenarios para la Universidad}

El mundo viene experimentando transformaciones tan radicales, que prácticamente no existen áreas de la sociedad que no se hayan visto afectadas y la educación, por supuesto, no es la excepción. Castells afirma que está surgiendo a nivel mundial una estructura social asociada a un nuevo modo de desarrollo que denomina "informacionalismo", que reestructuró el capitalismo y comenzó a trasformar los procesos de producción, la experiencia humana y el poder, como ejes centrales del acontecer social. En este nuevo "modo de producción informacional", la fuente de productividad radica fundamentalmente en la tecnología, en la generación de conocimiento, las formas de procesamiento de la información y la comunicación de símbolos (Castells, 1997).

Las características básicas de este nuevo paradigma implican un modelo de cambio continuo y de fluidez en las demandas, la producción y el consumo. Los rasgos centrales se relacionan con la alta capacidad de penetración de las nuevas tecnologías de la información, que tienden a modelar crecientemente la existencia individual, la lógica de interconexión de todos los sistemas que utilizan las nuevas tecnologías y que han determinado el surgimiento de una nueva morfología de interrelaciones denominada "sociedad red" y la alta flexibilidad que implican capacidades de adaptabilidad de reversión y reestructuración sin precedentes.

Se generan transformaciones históricas de gran magnitud y profundidad que implican modificaciones radicales, no sólo en la esfera económica, académica y tecnológica donde se originaron, sino que en todos los ámbitos institucionales de las sociedades contemporáneas, generando fuerzas que conllevan cambios conductuales profundos en los individuos que realizan su acción en ellas. Desde una perspectiva histórica, la instauración de la sociedad red representa un cambio cualitativo de la experiencia humana y lejos de ser el fin de la historia, es su comienzo, pues representa una nueva era de la información, marcada por la autonomía de la cultura frente a las bases materiales de nuestra existencia. En ese sentido, 
es una sociedad donde por primera vez la información actúa sobre sí misma como principal forma de productividad, modificando por completo los entornos en los cuales operan las dinámicas del trabajo y por ende los procesos formativos y educativos (Castells, 1997).

Al observar la globalidad del cambio y el consecuente incremento de la complejidad interna de los sistemas sociales y su entorno se constata un marcado sentimiento de perplejidad que se aprecia a la hora de plantear caminos de solución o alternativas para la adaptación de la universidad en la era de la información, a las nuevas necesidades que se generan y las competencias que se requerirán en el futuro próximo (Imbernón, 2002). Se produce una aceleración del presente que impide un adecuado asentamiento, lo que a su vez resta valor referencial del pasado y hace que el ritmo de la vida se incremente, siempre al borde del abismo y siempre abocados al futuro (Gimeno, 2002). Viviríamos un "traumático cambio de paradigma", pues las finalidades que se perseguían en la sociedad industrial y que las demás instituciones, incluida la educación, con sus fines y procedimientos incentivaban, se han modificado radicalmente en el marco de la S.I. (Donoso, 1999). Ello ha significado una acelerada mutación con rasgos ambivalentes que "incuba amplias perspectivas de progreso a la vez que entraña devastadoras secuelas sociales" (Perinat, 2004, p. 136).

Como las operaciones básicas de la universidad se encuentran directamente relacionadas con la producción, el almacenamiento, la transmisión y la crítica de la información, se sostiene con frecuencia, que ante la inminente generalización de las nuevas TICs y los cambios productivos y sociales, estas cuatro funciones acabarán viéndose profunda e inevitablemente afectadas (Ferraté, 1998). Más allá de la sensación de perplejidad que se percibe en muchos de los actuales planteamientos sobre el tema, una constante se refiere a la ineludible necesidad e incluso obligatoriedad de la innovación continua, en un ambiente donde lo único seguro es el cambio permanente.

Pero las adaptaciones no pueden ser al azar, deben ser capaces de servir como marcos adecuados para la acción de los sistemas y permitir la reducción de la complejidad del entorno (Luhmann, 1996). En una sociedad compleja, los sistemas especializados en procesar conocimiento, producirlo y reproducirlo, se tornan cruciales, no sólo para las personas que buscan nuevas oportunidades en futuros empleos que se espera exijan competencias que actualmente ellos no tienen, sino también para diversos subsistemas 
sociales que de una u otra forma buscan información especializada, innovación tecnológica, investigación aplicada, entre otros insumos.

En los países que conforman el G-7, ya se verifica no sólo el cambio en los procesos productivos, sino también una tendencia común hacia el aumento del peso relativo de la ocupación informacional (Flecha y Tortajada, 2002). Algunas importantes mutaciones previstas aluden al hecho que el rápido desarrollo supondrá una progresiva descentralización de estructuras a todos los niveles, se incrementará la especialización de las destrezas y requisitos laborales, así como la individualización de los intereses. La movilidad continuará aumentando, pero se elevará más la movilidad electrónica que la física, requiriéndose por tanto que la educación se dote de nuevas estructuras, agentes y formas de gestión.

Para las universidades, estas transformaciones resultan casi siempre problemáticas, pues se agudiza la tensión interna del sistema en la medida que no se abandonan fácilmente las disposiciones frente al entorno. Además, se busca un conocimiento útil, gestado en la acción, orientado a resolver problemas; en definitiva un nuevo modo de producir conocimiento. Es un conocimiento que requiere otro contexto de aplicación, el cual es transdiciplinar, heterogéneo, móvil y no jerárquico (Buendía, 2003.; Perinat, 2004). Por supuesto, no resulta fácil efectuar una síntesis del conjunto de cambios y efectos que han tenido lugar en las universidades. Zabalza considera que se pueden resumir en seis grandes retos a los que la Universidad actual debe hacer frente en sus planes de acción:

1. Adaptarse a las actuales demandas del mundo del empleo, ofreciendo una formación, que sin renunciar a los contenidos básicos, capacite a sus estudiantes a un fácil acceso a la oferta laboral.

2. Situarse en un nuevo contexto de competitividad social dónde va a primar la calidad y la capacidad para establecer planes e introducir ajustes.

3. Mejorar la Gestión, en un contexto de reducción de recursos públicos que exige la incorporación de nuevas fuentes de financiación y una mayor transparencia en la distribución de los mismos.

4. Incorporar las nuevas tecnologías tanto en la gestión como en la docencia y aprovechar su potencial para generar nuevas formas de relación interinstitucional y nuevos sistemas de formación (redes virtuales, enseñanza a distancia, etc.) 
5. Constituirse como motor del desarrollo local tanto en lo cultural como en lo social y económico a través del establecimiento de redes de colaboración con empresas e instituciones.

6. Reubicarse en un nuevo escenario globalizado de formación y empleo y adaptar a él sus propias estrategias formativas: potenciando la interdisciplinaridad, el dominio de lenguas extranjeras, la movilidad de estudiantes y profesores, la investigación, los programas y sistemas de acreditación compartidos, etc. (Zabalza, 2002). Estas expresiones resultan en muchos casos aún sólo deseos de buena voluntad, pues el proceso de ajuste recién parece estar comenzando. Aún no existe una visión panorámica que permita vislumbrar los grados, ritmos y dimensiones de las actividades universitarias que se están adaptando con mayor claridad a los cambios referidos.

\subsection{Universidad y era de la información en Latinoamérica y Chile}

Evidentemente, el advenimiento de un nuevo orden socioeconómico a escala global no se vivencia del mismo modo en todos los contextos sociales. Por lo tanto, la relación entre universidad y era de la información estará ineludiblemente mediada por las particularidades en que dicho proceso ha ocurrido en América Latina y en cada sociedad nacional.

En Latinoamérica se evidencian avances, pero a la vez nudos importantes en la transición al informacionalismo como nuevo modelo de desarrollo. Las estrategias encaminadas a facilitar esta transición incluyen, por una parte, la creación de una infraestructura tecnológica adecuada con el esfuerzo público y privado; por la otra, la promoción de recursos humanos que impliquen una verdadera reforma educativa en todos los niveles, puesto que la educación es la principal inversión en la era de la información.

Aunque estos rasgos generales se comparten en todos los países de la región, su importancia cambia según el contexto específico. Hay países que entran en un esquema de exclusión globalizante o exclusión de la globalización, y otros que se han insertado en ese proceso de forma relativamente autónoma. "El caso más importante de inserción dinámica y autónoma en la globalización es el de Chile" (Castells, 2005, p. 404). Sería un caso cuyo análisis tiene relevancia para el conjunto de América Latina, ya que, a pesar de las limitaciones y contradicciones que se pueden observar, el país presenta un balance de progreso económico, social y político continuado en la última década y media. Ha adoptado como política diversificar sus relaciones globales, mediante su capacidad exportadora y 
competitiva, reforzando su inserción productiva con información, tecnología y mejoramiento de la gestión empresarial. Expresaría además un "modelo democrático liberal incluyente", con un tipo de desarrollo gestionado a partir de un Estado democrático y que manteniendo los mecanismos de mercado como forma esencial de asignación de recursos, implementa políticas públicas encaminadas a la inclusión del conjunto de la población (Castells, 2005).

La aplicación de este modelo generó logros económicos y sociales, mejorando substancialmente un conjunto de indicadores nacionales, como el aumento sostenido del PIB, la conformación de estructuras que hablan de un proceso modernizador a través de una renovación institucional, cambios demográficos, disminución de los niveles de pobreza y el acceso a bienes y servicios por parte de los sectores más desfavorecidos, mayor incorporación de la mujer al mundo del trabajo, diversificación y tecnificación de las actividades económicas, tecnificación, liberalización de las costumbres y transformaciones en las expectativas de la población (Tironi, 2003).

Pero el país presenta importantes debilidades contextuales. Mantiene grados altos de desigualdad de la renta, considerables disparidades en la calidad de la educación que reciben los diversos estratos sociales, diferencias socioeconómicas y de infraestructura regional, insuficiente cobertura de pensiones y limitada incorporación de tecnología a los procesos productivos. A pesar de ello, "una buena parte de los elementos básicos del modelo informacional está ya en vías de consolidarse en Chile" (Castells, 2005, p. 106).

Es necesario que el país enfrente un conjunto de procesos de innovación para hacer sustentable el modelo, que no sólo pasan por el desarrollo tecnológico y la amplificación de las redes empresariales, sino que se debe transformar la producción de conocimiento y a las universidades en actores centrales en la formación de fuerza de trabajo informacional. Urge una "recualificación masiva de la fuerza de trabajo" (Castells, 2005, p. 108).

Ese es justamente el punto débil de Chile, puesto que el país muestra retrasos respecto de otros países del continente y, por supuesto, respecto de los más desarrollados, en cuanto a: cantidad de graduados en ciencia y tecnología, grado y nivel de la producción científica, nivel de educación de la población adulta, formación en matemáticas y ciencia, bajo porcentaje de población competente en manejo de información, calidad de la enseñanza universitaria y escasa relación entre investigación universitaria y el mundo de la empresa.

Es altamente probable que al ámbito de asistencia técnica se torne cada vez más importante en la acción del sistema universitario chileno, pues no sólo permite fortalecer los 
vínculos y la conformación de redes entre las distintas unidades académicas con el sector productivo, sino que constituye un mecanismo para incrementar los propios recursos de las casas de estudios, en una época donde los aportes fiscales se encuentran en franca reducción y el incremento de la oferta ha implicado una drástica elevación de la competencia para captar matrículas del alumnado.

En lo que se ha denominado "la tercera misión de la universidad", se juega en el enlace entre las funciones emprendedora y de innovación, tornándose la universidad en motor de creación y transferencia de todo el conocimiento diseminado en su entorno (Etzkowitz, 2000; Schulte, 2004). Expresado de otro modo, la educación superior debe dirigir el proceso de transferencia del conocimiento orientado a la generación de innovaciones, formando una política de la cultura científica acorde al ámbito de la investigación capaz de transferir conocimiento y formar al mismo tiempo a los asesores y gestores científico-técnicos (Bueno, 2007).

Desde hace ya algún tiempo, existe preocupación en ciertos círculos universitarios en el sentido de que las transformaciones globalizadoras, sobre todo de sentido altamente "economicistas", signifiquen terminar con ciertos rasgos que se habían arraigado en las formas de vida en Latinoamérica. Como respuesta, algunos consideran que la universidad posee una gran responsabilidad, tornándose en una alternativa cultural frente al mercado con una contracultura basada en el respeto a la identidad cultural (Rojas, 1999). Paralelamente, la centralidad que ha adquirido el mercado en la actualidad, puesto que anteriormente ocupó el sistema político a través de la acción del Estado en Latinoamérica y Chile, viene estableciendo un conjunto de nuevas exigencias relacionadas con el incremento de la competencia y ajustes a las reglas de orden económico y financiero, a todas las instituciones sociales tradicionales y a los proveedores del sistema universitario (Rodríguez, 2003).

Los problemas no parecen situarse sólo en aspectos relacionados con un economicismo exacerbado o con las dificultades para la adopción y difusión tecnológica, avance científico insuficiente y las débiles adaptaciones educativas, pues como consecuencia de los desequilibrios del desarrollo vivido en Chile durante las últimas décadas, a pesar de los éxitos alcanzados a nivel de continente, "ha ido creciendo simultáneamente un cierto sentimiento de desazón e inquietud que varios autores ha llamado el malestar de la cultura" (Larraín, 2005, p. 180). Ello tiene que ver con una gran diversidad 
de aspectos aún poco esclarecidos. Entre los más repetidamente señalados se encuentra la disconformidad de la población con la persistente desigualdad socioeconómica del país, las contradicciones de un acelerado proceso de modernización, conflictos y dilemas éticos y una creciente sensación de inseguridad y riesgo detectados ya en la década pasada (PNUD, 1998).

En el marco de estas consideraciones, muchos especialistas del país asumen que la universidad tal como fue concebida está "obsoleta" o al menos se encuentra considerablemente "desalineada con los tiempos" (Brunner, 2008). La consolidación del modelo informacional, que ya se encuentra en marcha en Chile, exige impulsar estructuralmente la innovación. Para ello se requiere:

- Universidades o centros privados sin ánimo de lucro (fundaciones) con un nivel suficiente de excelencia como para estar en las redes mundiales de desarrollo científico y tecnológico.

- Producción de stock de conocimiento y de talento, con personas formadas y con la capacidad de convertirse en emprendedores o en fuerza de trabajo innovadora. Lo cual implica un esfuerzo considerable en la mejora de calidad del sistema universitario y en su flexibilidad.

- Programas de cooperación científica con empresas multinacionales y con universidades de punta en el ámbito mundial en los campos de especialización seleccionados.

- Programas de becas en el extranjero para posgraduados chilenos, con reinserción garantizada en buenas condiciones en Chile.

- Atracción de empresas multinacionales negociando prioritariamente transferencia de tecnología.

- Innovación significa libertad de creación y una cultura de la innovación. (Castells, 2005, pp. 107-108).

\subsection{Educación superior y difusión de las TICs}

Los cambios asociados al advenimiento de la S.I. generan sensibilidades, ritualidades, relaciones sociales, narrativas culturales e institucionalidades distintivas, que hacen que la tradición de los grandes "sólidos modernos" se trasmuten produciendo una novedosa relación adaptativa frente al complejo entorno de este nuevo escenario social. Dicho cambio 
no deviene por mera presencia en la construcción del conocimiento, debido a que la conectividad en sí misma no asegura que la comunicación sea provechosa ni resuelva automáticamente la interactividad didáctica en el campo del saber (San Martín, 2003 ; Area, 2005 y 2008). Las respuestas institucionales retratan experiencias de distinto tipo, tal como han enfatizado las contribuciones de Salinas (1997, 1998, y 2000).

Entre otras, se pueden señalar: programas de innovación docente en las universidades, relacionados sobre todo con la incorporación de las TIC en los procesos de enseñanza aprendizaje, modificación de las estructuras universitarias, en cuanto que comienzan a ser consideradas estas tecnologías en el organigrama y en los órganos de gestión de las universidades, y experiencias innovadoras de todo tipo relacionadas con la explotación de las posibilidades comunicativas de las TIC en la docencia universitaria.

Otro factor que prevalece es la mayor colaboración internacional en el ámbito universitario, ligado a los avances en las tecnologías de la información y la comunicación, lo cual modifica las prácticas, orientaciones y estrategias académicas utilizadas habitualmente hasta ahora. Una experiencia pionera en este ámbito fue la primera "ciberuniversidad", que ha visto otras experiencias similares a partir del año 2000. La Universitat Oberta de Catalunya, que basó su modelo educativo no presencial en el campus virtual, lo definió como el conjunto de múltiples funcionalidades que hacen posible la interacción entre los colectivos que componen la universidad (Ferraté, 1998). Otros ejemplos son las actividades denominadas Open Course Ware (OCW), que constituyen archivos de información que contienen los materiales de clase con códigos abiertos en la red. Estas experiencias pioneras fueron efectuadas por primera vez por el Instituto Tecnológico de Massachusetts (MIT), hacia el año 2001, sumándose posteriormente distintas universidades a nivel mundial.

En definitiva, se trata no de posibilitar titulaciones on-line, sino de potenciar la sociedad de la información y el conocimiento y potenciar vinculaciones posteriores que amplifiquen aplicaciones, redes o posibles proyectos mediante la difusión del material que se discute al interior de los centros de pensamiento y enseñanza.

En suma, tal como la evidencia empírica indica, las instituciones de educación superior han experimentado un cambio de importancia, desplazando de manera parcial, en ciertos casos y de manera más amplia en otros, los procesos de formación desde modalidades convencionales a entornos que involucran medios de enseñanza asistidos por computación, la utilización de modelos virtuales, bases de datos, multimedia, Internet, etc. En ese proceso, 
las universidades han procesado las demandas sociales para que los estudiantes reciban las competencias para el aprendizaje continuo y simultáneamente potenciar las oportunidades para acceder a nuevos mercados, generando un conjunto de presiones hacia el interior del sistema educacional, que debe ajustar las prácticas de enseñanza y aprendizaje y la organización de los planes de estudio.

La centralidad que han adquirido estos procesos de transformación socioeconómicos, tecnológicos y productivas de la mano del avance de la sociedad de la información, viene estableciendo un conjunto de requerimientos sin distinción a todas las instituciones sociales tradicionales y a los proveedores privados del sistema universitario, se encuentren acreditados respecto de sus procesos o no. El particular modo en que este conjunto de transformaciones sociales ha influido en el sistema universitario, las formas en que cada institución en el marco de su propia autonomía reacciona ante la S.I. y las diversidad de perspectivas que sustentan los principales actores universitarios respecto de ellos, plantean un conjunto de interrogantes insuficientemente indagadas en la región.

Ello resulta particularmente evidente en un contexto de desarrollo periférico, donde las reflexiones y discusiones sobre las necesidades de adaptación a estas nuevas condiciones del entorno y la instauración del sistema de acreditación institucional son de reciente adopción. Estas dudas son particularmente cruciales en el sector privado de la educación superior, respecto del cual existe un menor grado de conocimiento acumulado en el país. Este sector educativo posee ya 36 universidades instituidas desde comienzos de la década de los ochenta en Chile y evidentemente el fenómeno no puede considerarse nuevo; sin embargo, se le suele tratar como un ámbito homogéneo cuando en la realidad posee distintos orígenes, misiones institucionales, tamaños, complejidad y formas de gobierno diversos (Fernández, 2009).

\section{Las opiniones del profesorado y alumnado universitario frente a la Sociedad de la Información}

En esta sección se presentarán los aspectos metodológicos y los resultados del análisis de la información obtenida de una encuesta representativa aplicada a una muestra de docentes y estudiantes de seis universidades privadas de la Región Metropolitana de Santiago de Chile. 


\subsection{Metodología del estudio}

El presente trabajo se basó en un estudio de carácter descriptivo-cuantitativo (Hernández, Fernández, Baptista, 2006), pues buscamos medir y caracterizar las opiniones del profesorado y alumnado sobre los diversos aspectos relacionados con las manifestaciones de la sociedad de la información en el país y al interior de la universidad y sus procesos más relevantes.

En función de los propósitos generales del estudio, se definió como universo, las universidades privadas chilenas del Área Metropolitana de Santiago que han tomado parte en el proceso de acreditación institucional convocado por la Comisión Nacional de Acreditación (CNA). Hasta el año 2008, se habían presentado un total de 45 universidades en todo el país al proceso entre privadas y tradicionales. De ellas, veinte corresponden a las universidades del sistema privado que tienen sede en el área metropolitana, en tanto catorce obtuvieron la acreditación.

Los criterios generales que orientaron la selección fueron los siguientes:

a) Considerar a Universidades Pertenecientes al sector privado de la educación Chilena: Como se sabe las universidades privadas constituyen uno de los sectores de más rápido crecimiento los últimos 20 años y en Chile ya concentran la mayor parte de la matrícula. Es importante considerar que recientemente se ha incrementado el debate referido a la calidad de este sector y el grado en que cumplen con la diversidad de funciones propiamente universitarias, pues se cuestiona su complejidad, en cuanto a que son universidades fundamentalmente docentes, el tipo de gestión de sus recursos, la reinversión en infraestructura y tecnología, así como también la reducida investigación que realizan, el acotado desarrollo de postgrados e innovaciones, el escaso aporte de nuevo conocimiento y que la formación de redes y su vinculación con el medio serían de un menor alcance que las universidades clásicas (Mora y Fernández, 2005; Monckeberg, 2007). No obstante, en el contexto nacional se dispone de escasísimos resultados de estudios empíricos en este sector y en especial en aquellos referidos a la relación con la S. I. y su despliegue en sus procesos internos.

b) Que las universidades privadas se hubiesen presentado a la acreditación y existiesen casos de Universidades acreditadas y no acreditadas por el sistema nacional vigente en el país. El sistema de aseguramiento de la calidad que se aplicaba a 
través de la CNAP, hoy CNA, permite distinguir desde la perspectiva de un organismo oficialmente reconocido por el Estado Chileno, el grado en que las instituciones universitarias cumplen con determinados propósitos vinculados a su misión y visión institucional y por lo tanto es posible diferenciar y comparar aquellas instituciones que muestran evidencias claras en el avance de un conjunto estandarizado de criterios. Ello permitiría disponer de una distinción potencialmente útil para conocer si se detentan diferencias respecto de este tipo de criterio formal en relación con los procesos que vinculan la educación superior con las transformaciones del la S.I. que constituye el propósito de esta trabajo.

c) Que las universidades pertenecieran al área Metropolitana de Santiago. Este criterio posee una doble orientación tanto conceptual como práctica. En términos teóricos se privilegió la RM toda vez que desde el enfoque de la SI, se supone que es en los sectores mas modernizados y centrales de un país donde la difusión y avances tecnológicos y de información y conocimiento de detectan con mayor claridad (Castells, 2005). Por otra parte, es necesario indicar que la mayoría de las universidades del sector privado que se encuentran en la capital y sus alrededores metropolitanos, así como la mayoría que se había sometido a la acreditación en el momento en que se realizó la selección.

d) Que la selección final de los casos incluyera a docentes y estudiantes. Al respecto es necesario recordar que en la actualidad predominan, al menos en Chile, estudios muy generales sobre la sociedad de la información, ya sean basados en datos secundarios, descripciones de bases de datos o análisis institucionales o de políticas públicas (Cantero, A. 1999; Cantero, C.; 2003, Castells, 2005). Son escasos los estudios que abordan directamente la mirada de los actores y prácticamente inexistentes los que consultan al profesorado y alumnado de universidades para analizar las repercusiones de las transformaciones al interior de las casas de estudios superiores.

Considerando los criterios anteriores, fueron elegidas al azar tres instituciones acreditadas y tres no acreditadas por la Comisión Nacional de Acreditación CNA de las 21 pertenecientes al sector privado. El procedimiento de selección implicó un proceso relativamente largo para obtener los listados totales de profesores y alumnos en cada 
universidad, debido a las aprensiones y reparos iniciales que demostraron los directivos, especialmente en cuatro de los seis casos. Ello fue superado asegurando el anonimato de la información, lo cual se refleja en el hecho que en ninguna fase se realiza alusión directa a los nombres de las universidades específicas seleccionadas, debido al compromiso alcanzado entre las autoridades universitarias y el investigador.

Composición de la Muestra de la Encuesta

\begin{tabular}{|c|c|c|}
\hline Universidad & $\begin{array}{c}\text { Muestra } \\
\text { Alumnado }\end{array}$ & $\begin{array}{c}\text { Muestra } \\
\text { Profesorado }\end{array}$ \\
\hline A (acreditada) & 67 & 24 \\
\hline B (acreditada) & 67 & 24 \\
\hline C (acreditada) & 67 & 24 \\
\hline D (no acreditada) & 67 & 24 \\
\hline E (no acreditada) & 67 & 24 \\
\hline F (no acreditada) & 67 & 24 \\
\hline Total & 402 & 144 \\
\hline
\end{tabular}

La muestra final de las unidades de análisis estuvo constituida por 402 estudiantes y 144 docentes, con un nivel de error muestral de $+/-5 \%$ y un nivel de confianza del $95 \%$, administrada durante finales del año 2009 y comienzos del 2010. Del total de docentes encuestados, $61,1 \%$ correspondió a hombres y 38,9\% a mujeres. Respecto de la edad, su promedio alcanzó los 49,2 años, se trata en general de personas de mediana edad, lo que coincide con los años de experiencia docente, cuyo promedio alcanzó a 18 años. Dicho dato indica que la mayor parte posee amplia experiencia en la docencia universitaria, aunque no necesariamente en la universidad privada en la cual se desempeña actualmente, pues el promedio en ellas alcanzó sólo a 5,51 años. Por otra parte, el 52,2\%, de los estudiantes son mujeres y $47,8 \%$ hombres. El promedio de edad de los estudiantes fue de 23,2 años, mientras que el tiempo en la universidad fue de tres años como promedio. 


\subsection{Principales resultados de la investigación}

a) Manifestaciones de la Sociedad de la Información en Chile

Un primer aspecto consultado se refirió a la posible manifestación de la S.I. en Chile. Los datos muestran ciertas diferencias en las opiniones del profesorado y alumnado, pues mientras los primeros consideran que este modelo social se encuentra presente en el país en un $68,06 \%$, los estudiantes estiman mayoritariamente que ello ocurre solamente de manera parcial en un $53,2 \%$ y de manera clara en un $30,67 \%$.
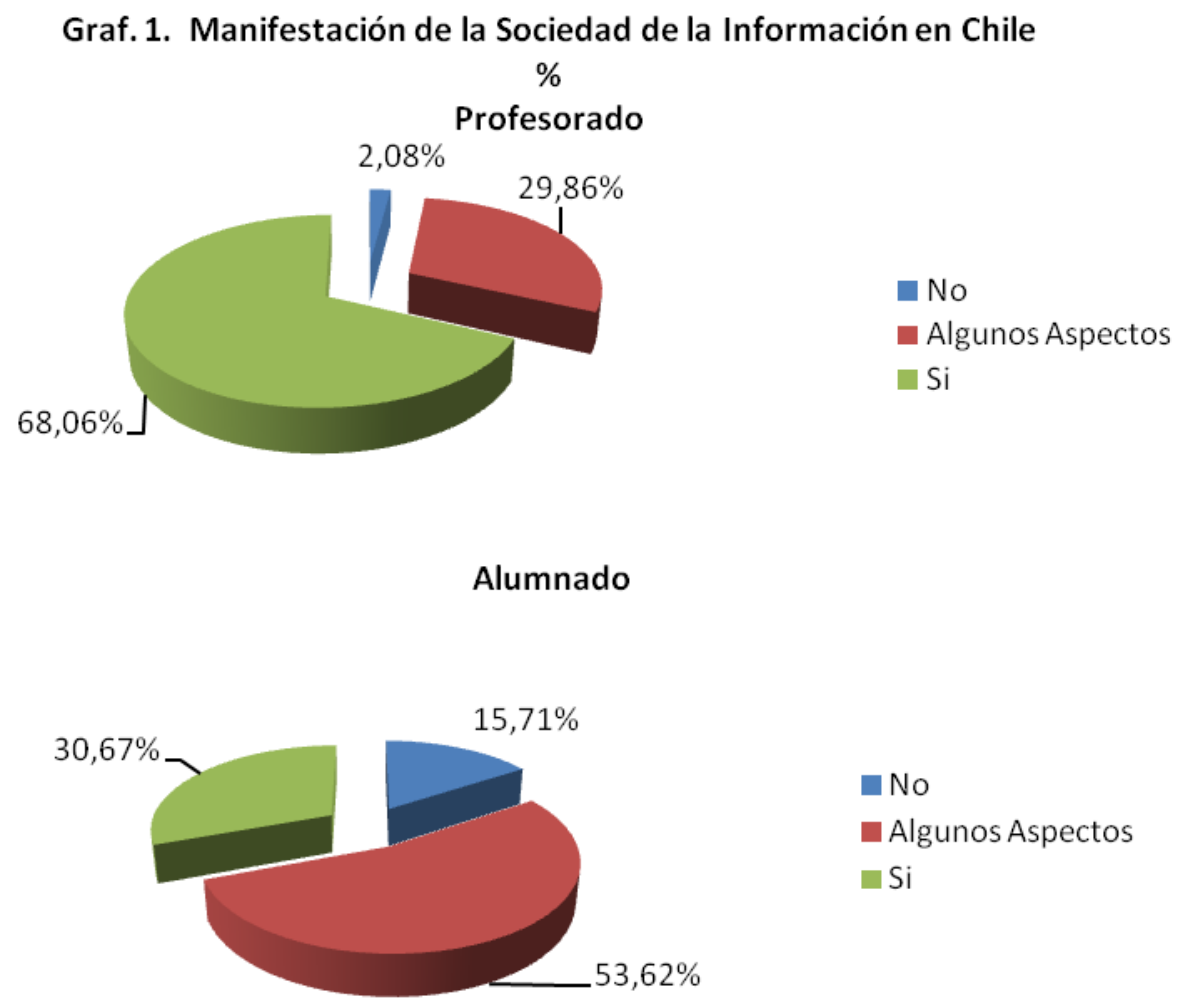

b) Nivel de conocimiento sobre la Sociedad de la Información

Cuando se consulta sobre el nivel de conocimiento que se cree poseer respecto de la sociedad de la información, los docentes mayoritariamente opinaron que conocían algo del tema $(54,17 \%)$, mientras que el $43,75 \%$, afirmó que lo conocía bien y sólo un $2,08 \%$ dijo encontrarse desinformado. Los estudiantes, por su parte, señalaron que conocían algo del tema en un $70,32 \%$ y, en segundo lugar, opinaron encontrarse desinformado $(15,71 \%)$, en tanto que una minoría afirmó conocer bien el tema (13,97\%). 
$2,08 \%$ Graf. 2 . Grado de Conocimiento respecto de la Sociedad de
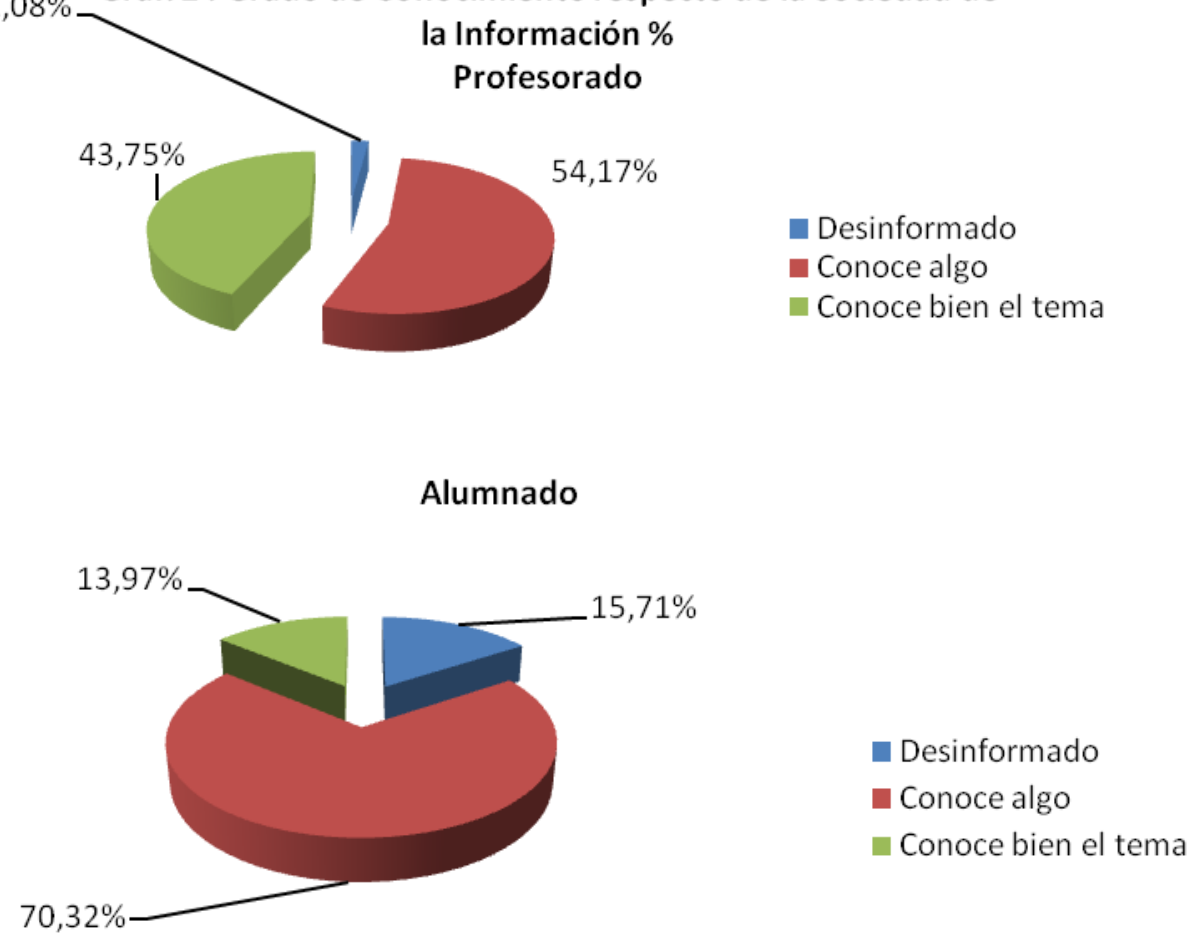

c) Formas de manifestación de la Sociedad de la Información

Ahora bien, al solicitar que los actores precisen la forma en que se manifiesta la S.I. en el país, existe bastante coincidencia, pues en las cuatro primeras mayorías, tanto docentes como estudiantes señalan las mismas respuestas de manera espontánea. La mayoría "no sabe o no responde" $(31,94 \%)$ entre los primeros y $(42,79 \%)$ en los segundos, a la vez que en ambos casos el porcentaje siguiente es seguido por "los medios de comunicación" (24,31\% en el profesorado y $28,36 \%$ en el estudiantado). Posteriormente, se señala que la S.I. se manifestaría mediante la presencia de "internet" (17,36\% entre los docentes y 17,16\% entre los alumnos). Con porcentajes inferiores, ambos estamentos se refieren a la "tecnología", la "publicidad", los "servicios públicos" y la "universidad", como otras realidades donde se aprecia la influencia de esta nueva estructura social. 
Graf. 3. Presencia de la Sociedad de la Información en Chile \% Profesorado

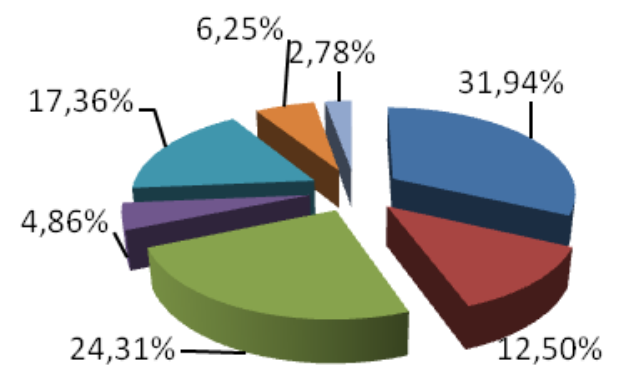

- No sabe/ No responde

- Tecnología

- Medios de Comunicación

- Publicidad

- Internet

- Servicios Públicos

- Universidad

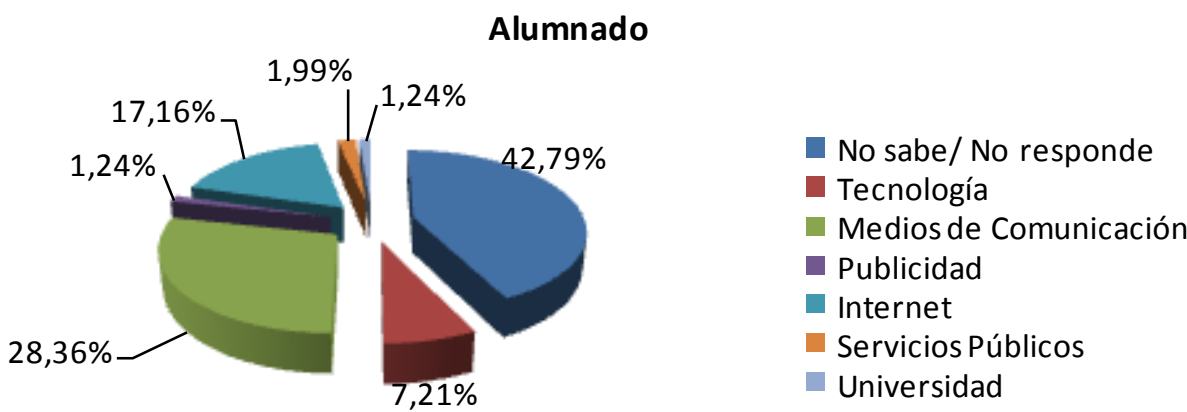

\section{d) Impacto de la Sociedad de la Información en la Universidad}

Una dimensión importante de conocer en el estudio decía relación con el impacto que ha tenido la S.I sobre un conjunto de aspectos relevantes de la universidad. En primer término, se consultó sobre los posibles cambios en los planes de estudio, observándose que el cuerpo académico y el alumnado coinciden en estimar mayoritariamente que la S.I. ha generado "pequeños cambios" (50\% y 39,8\%, respectivamente) o "cambios moderados" $(27,1 \%$ y $34,1 \%)$. Con porcentajes muy inferiores se plasman los juicios que consideraron que se apreciaban "grandes cambios" o "sin cambios". 


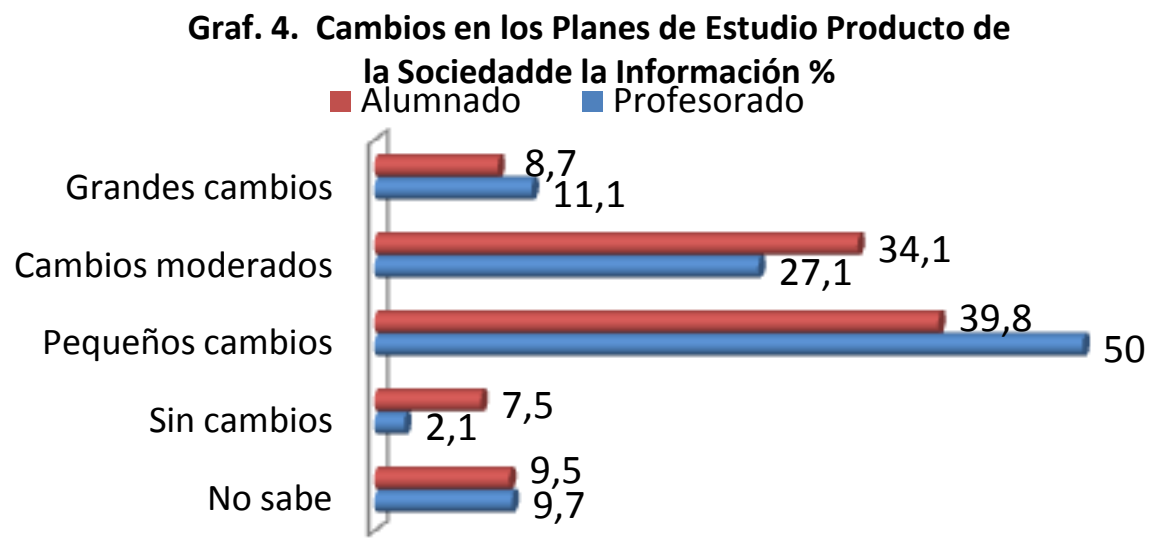

Cuando se indagó sobre el impacto en los sistemas de enseñanza-aprendizaje, las opiniones presentaron cierta variación, pues en este caso la mayoría de los docentes consideró que la S.I. ha traído aparejados "cambios moderados" en este aspecto (43,8\%), en tanto que la mayoría de los alumnos estimó que había generado más bien "pequeños cambios" (35,8\%). Quienes consideraban que se habían generado "grandes cambios" o no habían existido transformaciones, fueron porcentajes minoritarios en ambos casos.

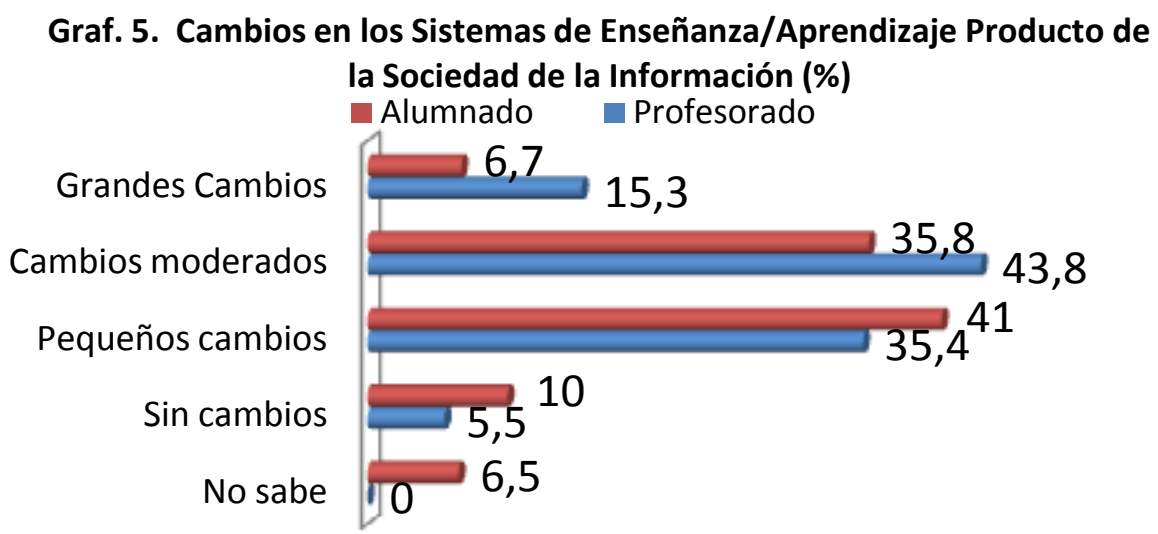

Respecto de las opiniones sobre la influencia en las creación de nuevas carreras, se aprecia una tendencia similar pero con algunas variaciones menores. Es así que a juicio de los docentes, los cambios han sido fundamentalmente "moderados" (31,9\%), en tanto que el estudiantado estima, en su mayor parte, que han existido solo "pequeños cambios" (28,3\%). Los docentes consideran en una segunda opción que no hay cambios $(25,7 \%)$, mientras que los alumnos creen que los cambios son moderados (26,8\%). Con porcentajes menores se 
expresan las opiniones que atribuyen grandes cambios en este aspecto de la acción universitaria.

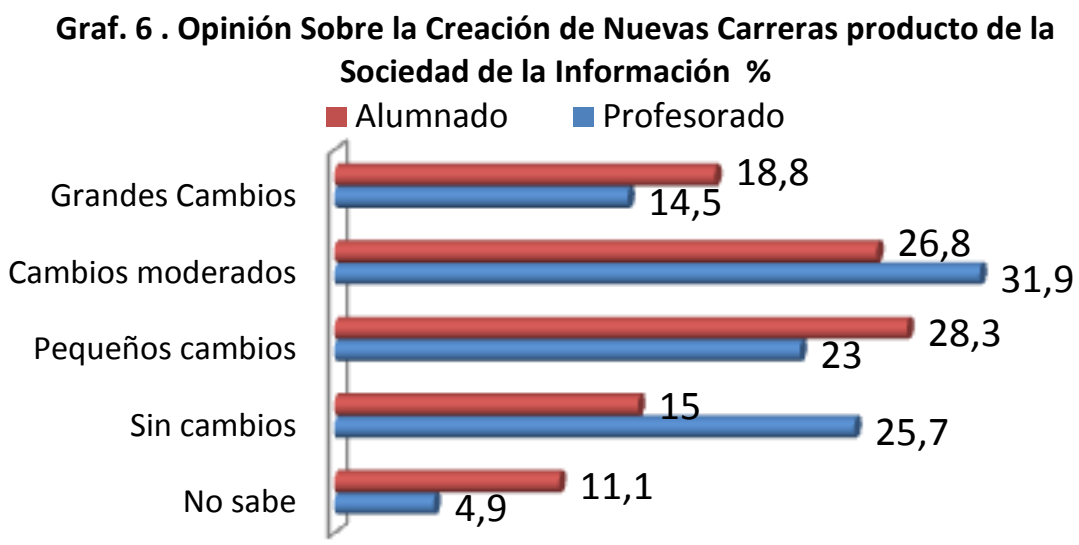

Sobre la creación o adaptación de cursos de postgrado o postítulo ante la influencia de la S.I., ambos estamentos concuerdan en que los cambios han sido "moderados": $39,6 \%$ en el caso de los docentes y $31,5 \%$ en el caso de los estudiantes. Porcentajes bastante cercanos se observan en la segunda mayoría de las respuestas, que señalan que dichos cambios han sido pequeños (25,6\% y $22,5 \%$, respectivamente). Cabe indicar que en el caso del alumnado, se eleva las respuestas que afirman no saber del tema $(28,2 \%)$. Nuevamente, quienes consideran que han existido grandes cambios acumulan porcentajes bajos.

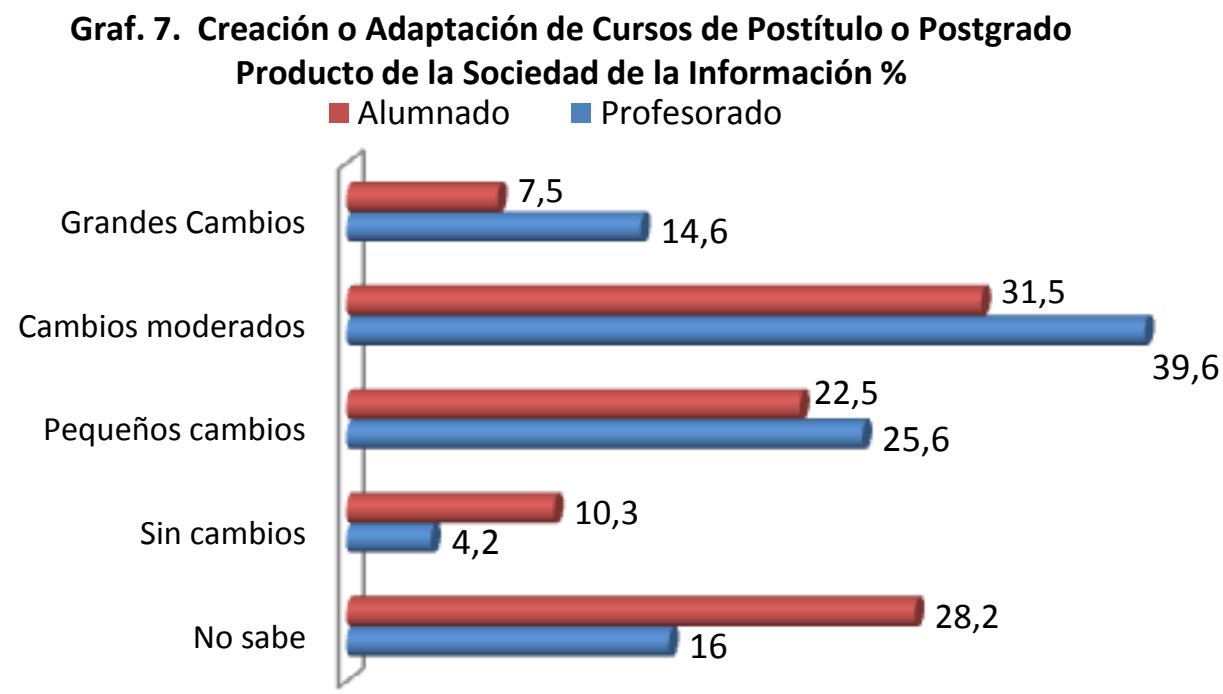


Al inquirir sobre los cambios observados en la administración universitaria como producto de la S.I., los docentes estiman mayoritariamente que las transformaciones han sido moderadas $(36,8 \%)$, mientras que los alumnos piensan en su mayor parte que son "pequeños" (35,8\%). Resulta interesante indicar que el $26 \%$ del estudiantado afirmó que la situación se encuentra "sin cambios", muy contrastante con la opinión del profesorado, que apenas seleccionan esta alternativa en un 2,8\%. En este tema, también el porcentaje tanto de profesores como de alumnos que consideran que se perciben "grandes cambios" es minoritario $(11,1 \%$ y $6,8 \%$, respectivamente).

Graf. 8. Cambios en la Administración Universitaria Producto de la Sociedad de la Información \%

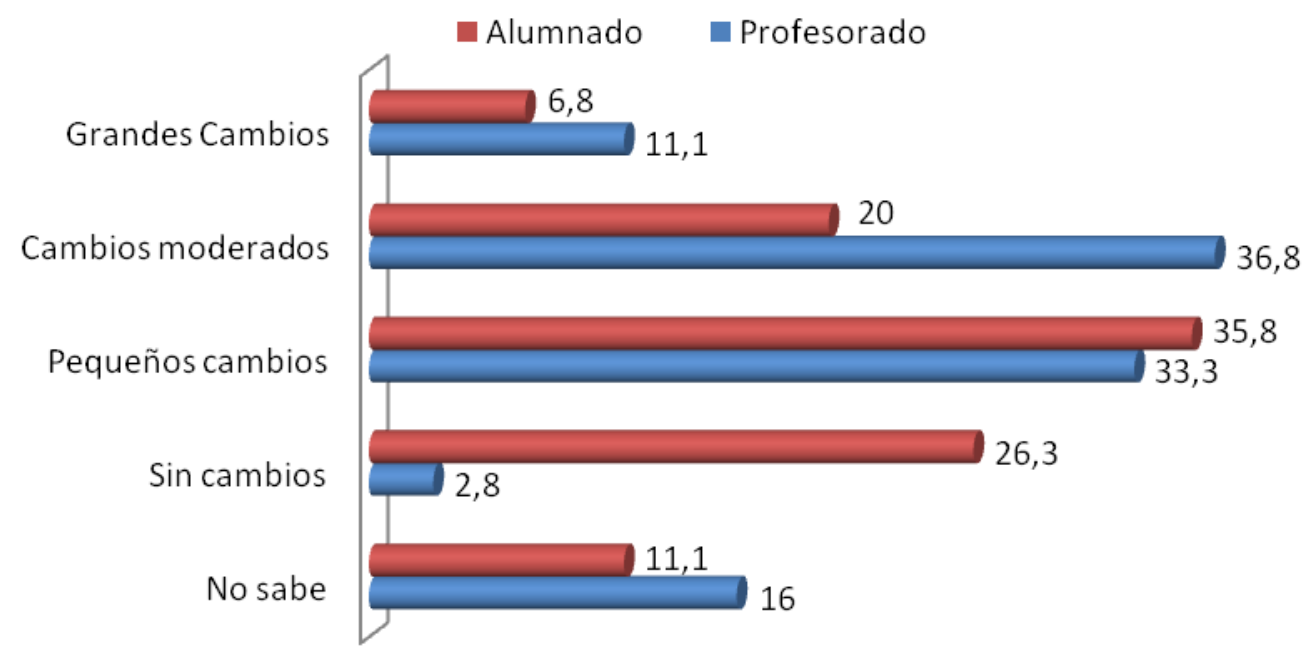

Respecto de la opinión sobre la influencia de la S.I. en la formación de redes y convenios de la universidad con el medio, predominó también entre académicos y estudiantes los que consideraron que los cambios eran moderados $(40,3 \%$ y $25,8 \%$, respectivamente), seguido por aquellos que estimaron que los cambios eran pequeños (25\% y $34,4 \%)$. En este aspecto, nuevamente los que aprecian "grandes cambios" son un porcentaje menor. 


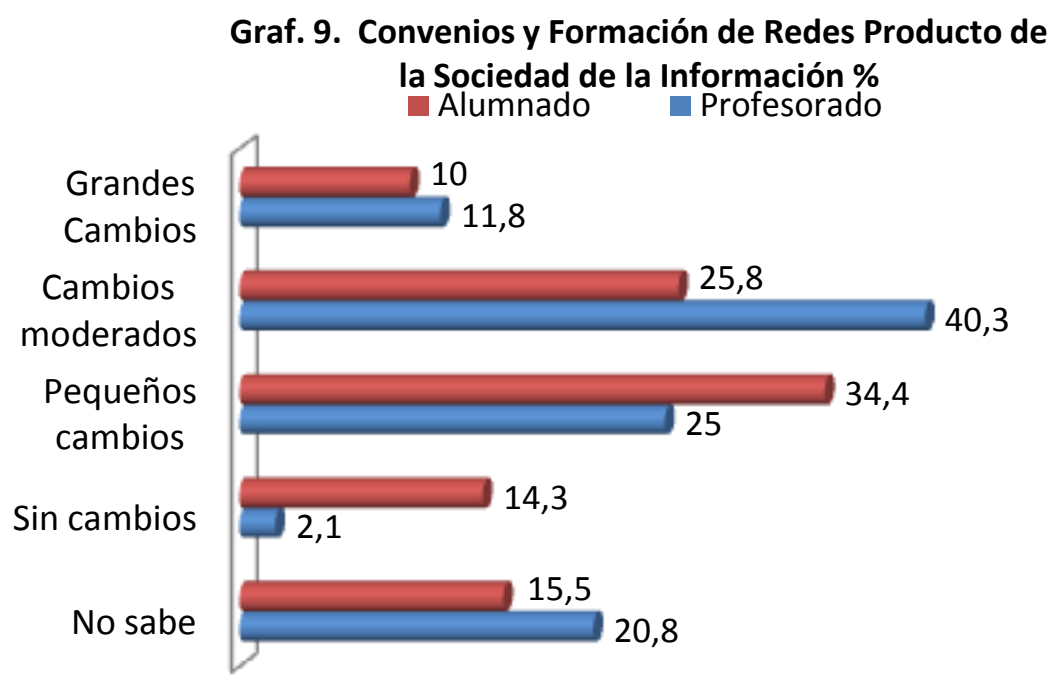

También se recabó información acerca de los posibles cambios que ocurren en la universidad asociados con la tecnología, como producto de la S.I.. Los docentes estimaron mayoritariamente que las transformaciones eran moderadas $(45,1 \%)$, mientras que los estudiantes opinaron que estas eran sólo pequeñas (36,1\%). En esta dimensión aumentaron en ambos estamentos, quienes consideraron que se habían experimentado grandes cambios en la tecnología de la universidad, atribuibles a la influencia de la S.I.. Llama la atención que sólo los alumnos estimaron en un 18\%, que no había existido cambio alguno.

Graf. 10. Cambios en la Tecnología de la Universidad Producto de la Sociedad de la Información \% Alumnado Profesorado

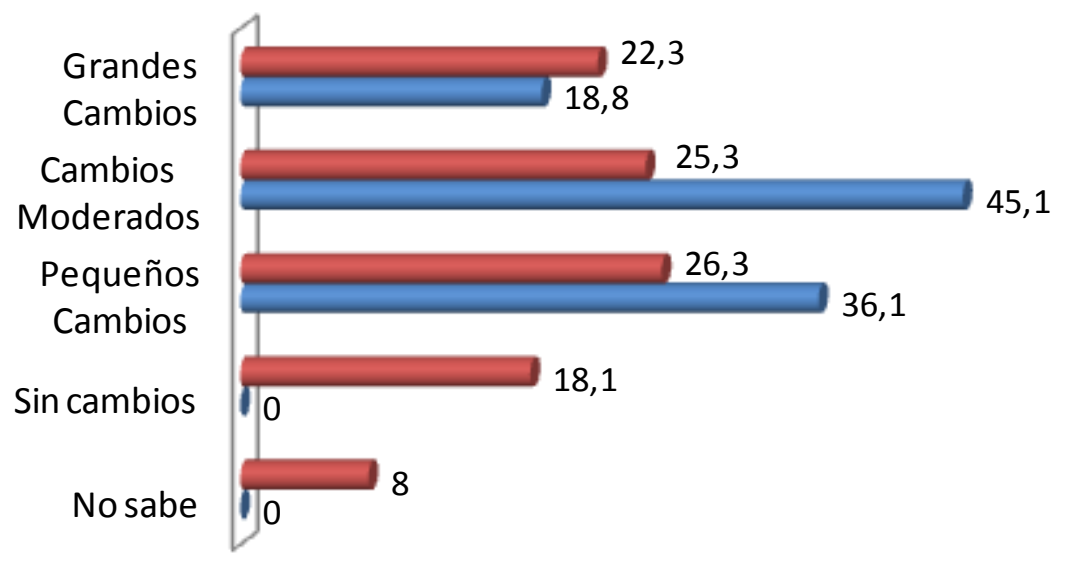


e) Factores que han obstaculizado la adaptación de la Sociedad de la Información

En este aspecto, los profesores tienden a discrepar con el alumnado. Es así que los académicos consideran que las "estructuras universitarias" (15,28\%), "la falta de interacción de la comunidad académica" (14,58\%) y el propio "cuerpo docente" $(12,5 \%)$, son los principales factores que han dificultado el ajuste. En tanto que consideraciones tales como "la acción de las autoridades", la "falta de programas de cooperación académica" y "la falta de innovación", son aludidos con porcentajes más bajos. Por su parte, los estudiantes consideran que "el cuerpo administrativo" (22,06\%), la "estructura universitaria" $(12,03 \%)$, la "escasez de recursos" (11,78\%) y "la falta de innovación" (11,53\%), son los principales factores que obstaculizan la adaptación de la universidad al nuevo entorno informacional.

Otras respuestas como "el cuerpo docente", la "falta de programas de innovación", la "falta de interacción con la comunidad académica" o "los alumnos", acumularon menores porcentajes en las preferencias de los jóvenes.

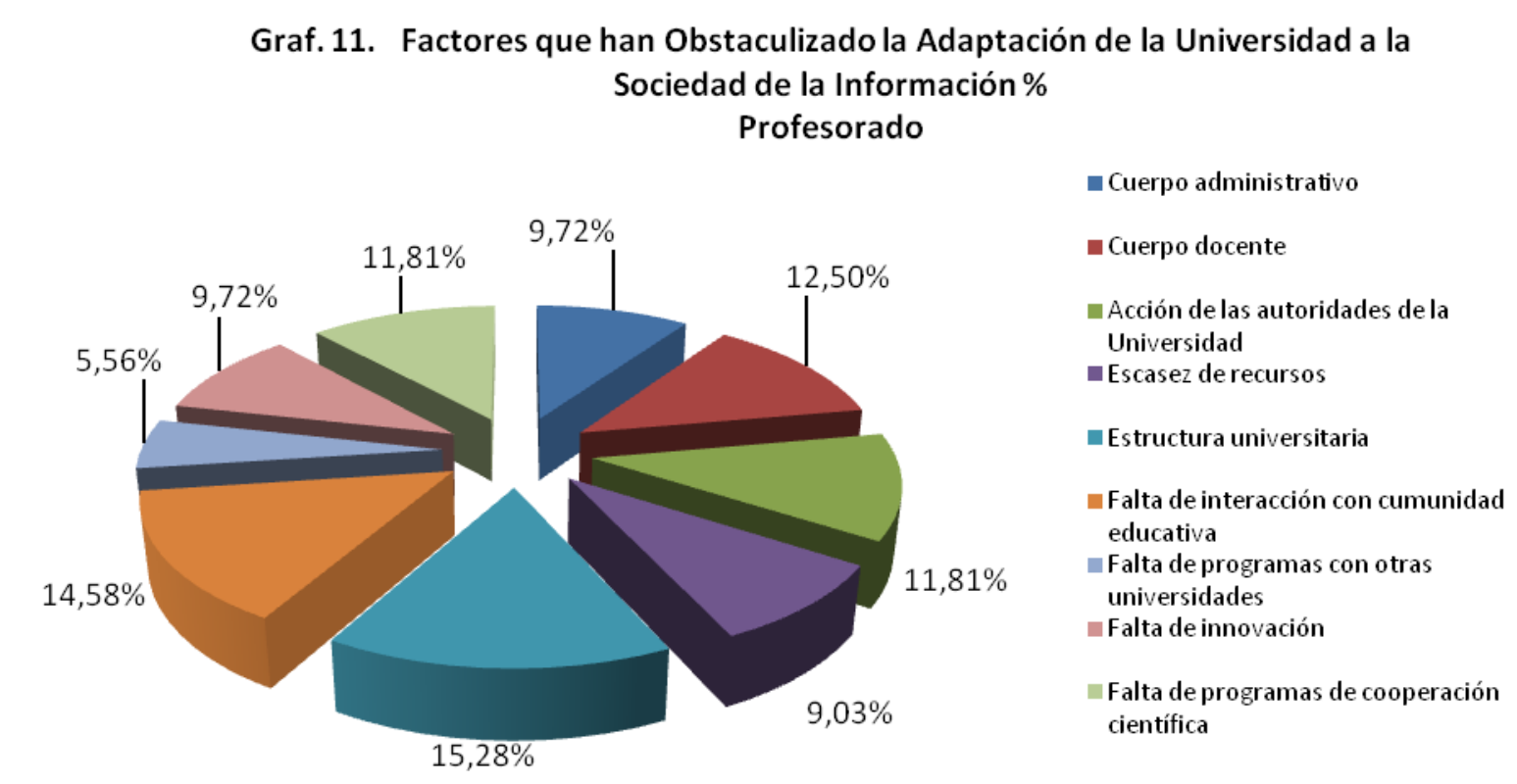




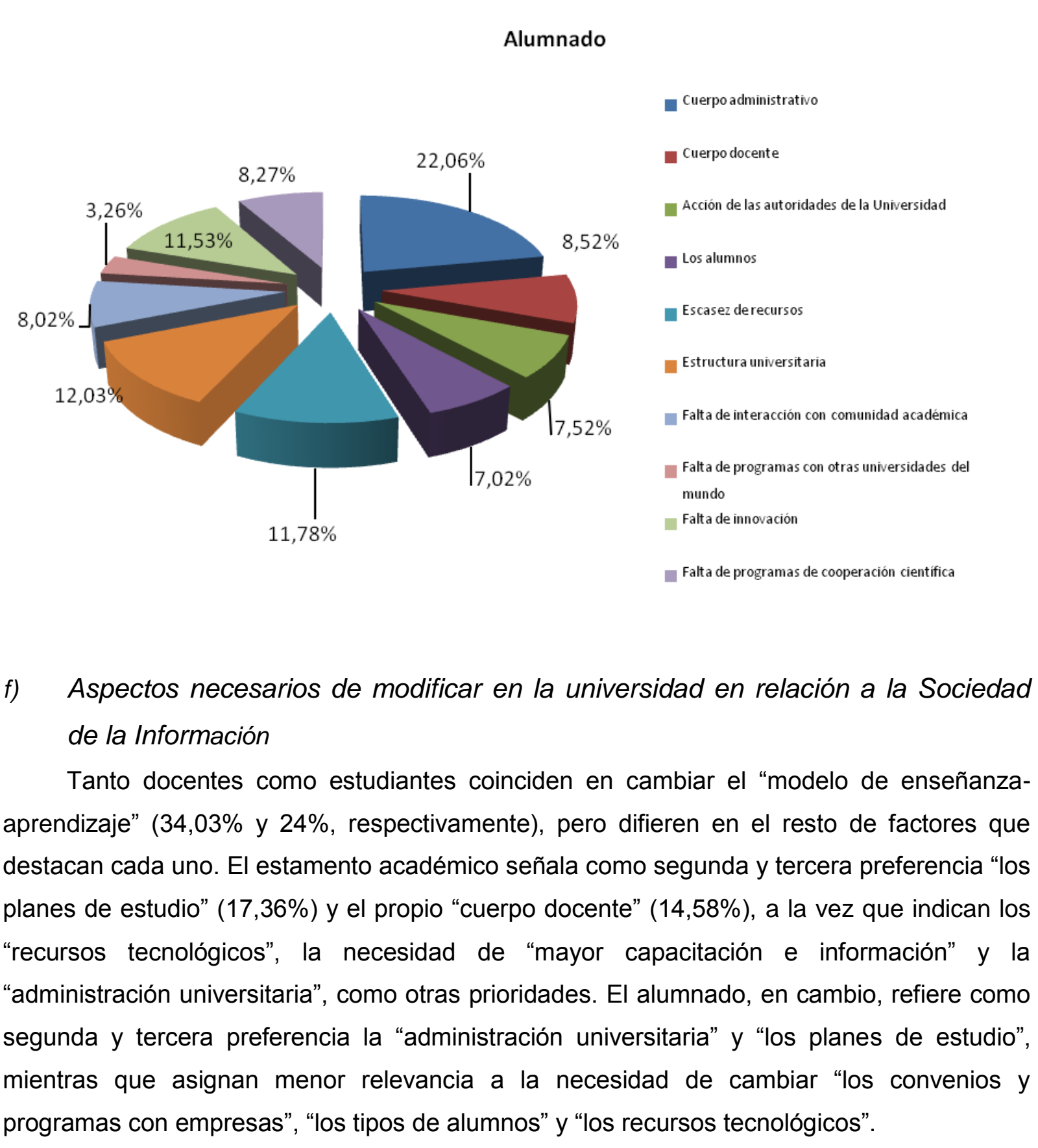




\section{Graf. 12. Aspectos que la Universidad debería Modificar teniendo en} cuenta la Sociedad de la Información \%
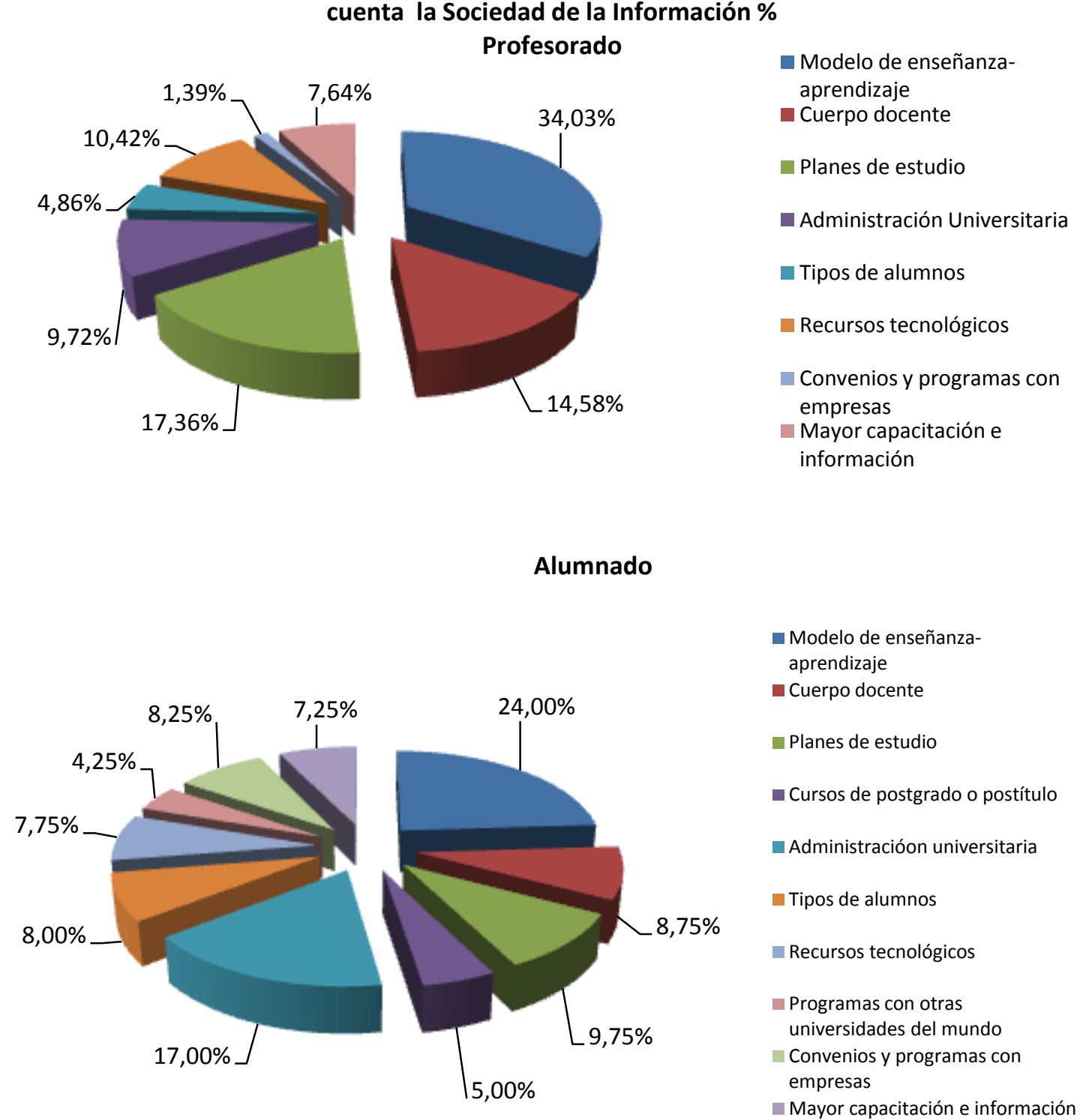

\section{g) Relación de la Sociedad de la Información con los procesos de Acreditación}

En el estudio también se consideró el parecer de los encuestados respecto de la posible relación entre las manifestaciones de la S.I. y el sistema de acreditación universitaria. En este caso, también ambos estamentos discrepan moderadamente, pues mientras los docentes afirman mayoritariamente que dicha vinculación existe $(62,28 \%)$, los estudiantes opinaron en su mayor parte que no había relación alguna (76,37\%). 


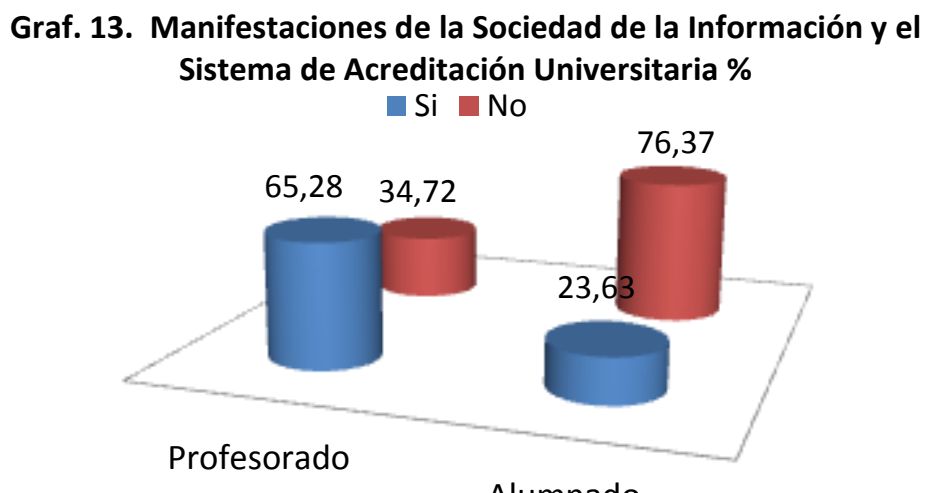

h) Atributos vinculados a la Sociedad de la Información

La última dimensión abordada en esta sección de la encuesta estuvo destinada a conocer la noción que ambos estamentos de la universidad poseen respecto de la S.I., como idea o concepto general. Para ello, se recurrió a la técnica del Diferencial Semántico, que consideró la elaboración y presentación de nueve pares de conceptos opuestos, que califican determinados aspectos de este modelo social.

Los resultados muestran un grado importante de coincidencia entre las respuestas de profesores y alumnos, reflejada tanto en los promedios generales como en las variaciones en cada par de conceptos. La noción que poseen ambos actores sobre la temática consultada, sin ser completamente favorable, tiende a asociarse en mayor medida hacia los polos positivos, lo cual queda en evidencia en ambos promedios generales. Sin embargo, se observan algunas diferencias importantes, entre las cuales están las evaluaciones asignadas a los calificativos "productiva-improductiva", donde los docentes alcanzan un puntaje de 5,78 en sus respuestas, mientras que los alumnos sólo promedian 4,96 puntos.

Algo similar ocurre en los opuestos "útil-inútil", donde el cuerpo de académicos asignó un puntaje promedio de 6,04 y los estudiantes, en cambio, 5,4; en el par "dinámica-estática", los puntajes promedio obtenidos son de 6,13 y 4,95, respectivamente. Para los docentes, los rasgos más positivos atribuibles al concepto S.I. serían, entonces, "productiva”, "útil” y "dinámica". Mientras que las características negativos más evidentes serían "lejana", "compleja” y "competitiva”. En cambio, los aspectos más positivos asignados en opinión de los estudiantes serían "útil", "importante" y "dinámica". En tanto que los atributos más negativos serían "compleja", que "genera incertidumbre" y "competitiva". 


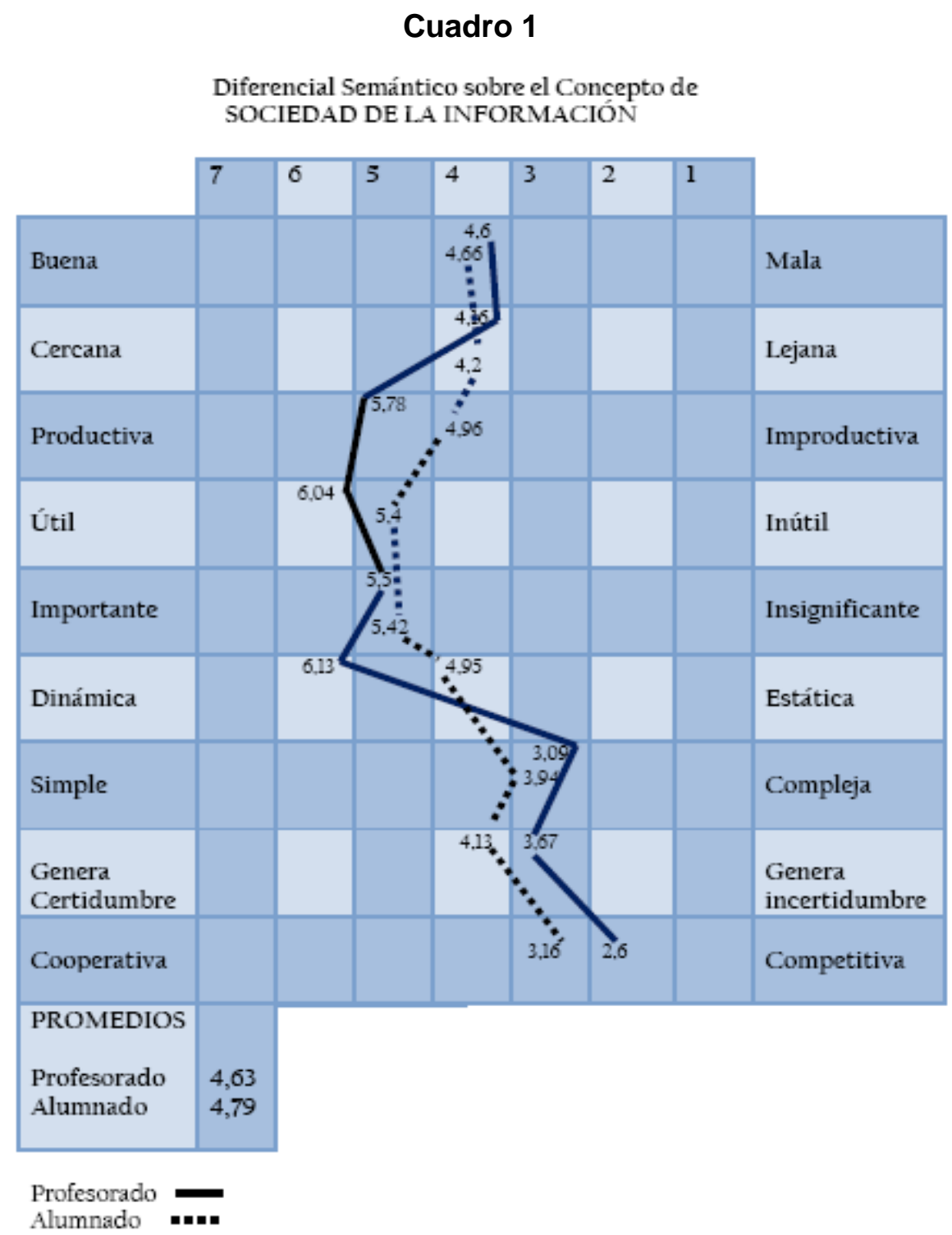

Un aspecto central de la investigación buscaba determinar diferencias entre las universidades que habían obtenido la acreditación institucional de la CNA, respecto de aquellas otras que no la lograron. La mayor parte de los factores considerados en el estudio no mostraron diferencias entre ambos grupos. En relación a las diversas dimensiones abordadas acerca de la S.I., no se observan mayores diferencias entre ambos tipos de universidad; sin embargo, sólo en el diferencial semántico es posible captar algunas sutiles diferencias. Es así que los estamentos de docentes y estudiantes de universidades acreditadas promediaron de manera levemente superior $(4,66)$, en sus evaluaciones generales sobre la S.I. respecto de los no acreditados $(4,46)$. 


\section{Conclusiones}

A la luz del conjunto de estos resultados, los estamentos universitarios al interior de las universidades privadas estudiadas reconocen, a nuestro entender, lo que denominaremos un Informacionalismo de Transición, tanto a nivel del país como en las manifestaciones que poseen las transformaciones globales. Esta interpretación es consistente con el marco referencial del estudio, tanto en el plano de las manifestaciones generales del modelo informacional para el caso latinoamericano y chileno en particular, como en la influencia que los especialistas advertían para las universidades en general.

La presencia de distinciones unívocas respecto de la S.I. pueden interpretarse conceptualmente como una manifestación creciente, donde esta manifestación se despliega en toda la sociedad y, por lo tanto, constituye un "entorno" para el sistema educativo. Es así que con escasas diferencias, el cuerpo académico y estudiantil coinciden en la presencia del modelo, sus alcances y los aspectos positivos y negativos que presenta, no observándose mayores discrepancias según tipo de universidad privada o los resultados obtenidos en la acreditación institucional de sus respectivos planteles.

Los datos revelan, además, una aceptación bastante generalizada del modelo informacional, no detectándose posturas de resistencia, sino claramente de adaptación, que propugnan por más herramientas y esfuerzos para desenvolverse adecuadamente, tales como: modificar los procesos de enseñanza-aprendizaje, adaptar los planes de estudios; desarrollar más capacitación en todos los niveles; incorporar personal especializado, ampliar la conformación de redes y elevar la disponibilidad y renovación de tecnología de punta.

Todo ello sería coherente con la actividad propia del sistema educativo y las diferencias no se deberían observar en el reconocimiento de la sociedad de la información misma sino en la forma en que cada organización educativa, dadas sus particularidades, puede reaccionar o entender sus actuaciones frente a esta condición del entorno.

Efectivamente, es en este plano donde se detectaron diferencias entre los acreditados y los no acreditados, toda vez que entre los primeros se aprecia una atribución de mayor impacto del modelo, en cuestiones especialmente del equipamiento tecnológico de la universidad, a diferencia de los segundos, que observan carencias en sus propias organizaciones y asumen que este modelo, si bien reconocen se encuentra presente en el país, ha tenido un menor impacto entre ellos. 
Las diferencias en la forma como los sujetos entienden el impacto que el modelo informacional está teniendo en sus propios ámbitos de actividad, se encuentran efectivamente previstas desde la teoría. Es así que, por ejemplo, Castells estima que el tránsito hacia el informacionalismo en el contexto latinoamericano en general y en Chile en particular, enfrenta dificultades vinculadas justamente con las carencias de una infraestructura tecnológica adecuada, la promoción de recursos humanos y una reforma educativa, particularmente en el concierto universitario, además de problemas persistentes de gestión burocrática y de obsolescencia administrativa en las organizaciones (Castells, 2003).

La presencia de contrastes, de aspectos favorables pero, a la vez, de amenazas asociadas a la S.I., constituye un aspecto que había sido también aludido por otros especialistas y que estaría siendo detectado por los principales actores a quienes les toca la vivencia directa de los procesos de transformación. En el caso chileno, se advierte que si bien el modelo se encontraría en desarrollo, subsisten importante trabas para la innovación, restricción de las redes, la necesidad de "recualificar" la fuerza de trabajo y la presencia de una fuerte inequidad social, que obstaculizan las capacidades para generar conocimiento y que ponen en riesgo la sustentabilidad del modelo (Castells, 2005).

Autores internacionales como Salinas (2000), Lapiedra (1998), Bricall (1998), De Luxán (1998), Marqués (2000), Zabalza (2002), Margraves (2003) y Bergero y Esnaola (2006), expresan con claridad como la S.I. y las transformaciones que han ocurrido en las últimas décadas, penetran y transforman sustancialmente las estructuras universitarias a nivel internacional. Esa evidencia acumulada a nivel internacional muestra una considerable distancia en cuanto a lo que es posible advertir en el contexto latinoamericano, pues los especialistas han remarcado las carencias económicas y en la infraestructura disponible, además de las debilidades de carácter formativo del recurso humano en la región para asimilar las nuevas tendencias.

Por otra parte, en el caso chileno, autores como Lavados (1990), González (1994), Brunner (2007, 2008), Riveros (2002), entre otros, indican que la recepción de la globalización y el informacionalismo al interior de las universidades nacionales es aún débil, enfrentando un conjunto importante de restricciones e imponiendo, por tanto, grandes desafíos futuros. 
Predomina así una perspectiva dual entre profesores y estudiantes de planteles privados que, por una parte, valora el modelo informacional reconociendo sus ventajas y potencialidades futuras, pero que, a la vez, genera aprehensiones en muchos actores que lo visualizan como complejo, incierto y excesivamente competitivo, lo cual podría reforzar actitudes de temor o tendencias a aferrarse a esquemas tradicionales de acción.

No obstante, las conceptualizaciones y evidencia empírica acumulada no permiten dimensionar de forma específica el alcance de estos resultados en el marco del particularismo del sector privado de la educación superior, puesto que en su mayor parte han sido pensadas para las expresiones mas tradicionales del mundo universitario y particularmente de las instituciones estatales.

Es necesario recordar que las universidades privadas se masificaron en Chile a partir de la década de los ochenta y por tanto constituyen planteles con escasa tradición y que en su mayor parte han evolucionado como universidades fundamentalmente docentes y sólo recientemente desarrollan, en forma compleja, las demás funciones universitarias, especialmente, investigación, publicaciones, relaciones con el medio, extensión, transferencia tecnológica, etc. Si bien es cierto que hoy concentrar la mayor parte de la matrícula universitaria, siguen mostrando indicadores que las ubican muy por debajo de las instituciones públicas y también denominadas tradicionales, que lideran los niveles de calidad en el país.

Si bien es cierto que todas las universidades enfrentan el mismo ambiente cambiante y transformador de la S.I., la construcción del entorno que cada una de ellas es particular y autorreferente, siendo relevante explorar con mayor detalle este desconocido sector de la educación superior en Chile y caracterizar la heterogeneidad estructural que hoy vemos en el sector. Intuimos que la vivencia cotidiana de docentes y estudiantes de las transformaciones que puedan experimentar de un modelo transicional de la S.I. se sustenta en distinciones y códigos difusos.

En la medida que las otras funciones distintas a la formación de pregrado se encuentran menos arraigadas en las prácticas privadas, involucran a un menor número de personas con permanencia (pensemos que en este sector predomina aún en Chile, el docente por horas o part-time) y aún expresan un nivel de sedimentación del sentido bajo, cabría esperar menos huellas organizacionales que gatillen un número alto de conexiones de significado entre los estamentos universitarios. Por esta razón, si bien es cierto que los 
actores reconocen aspectos claves del proceso de cambio, ligado a las transformaciones informacionales, hipotetizamos que, el grado de importancia atribuida, la centralidad para la actividad universitaria en toda su complejidad o los alcances futuros pueden apreciarse con menor grado de claridad que lo que podría ocurrir en las instituciones de mayor tradición y complejidad organizacional.

Nos asiste la convicción de que los procesos de transformación universitaria no ocurren en el vacío social y que su utilidad, congruencia y posibilidades de desarrollo futuro, dependen de los actores como protagonistas de las iniciativas de cambio y las heterogéneas condiciones en las cuales se desenvuelven sus actividades. La educación y la misión central como institución universitaria, probablemente no se ha modificado sustancialmente, en términos de su significado abstracto de universidad, con un carácter mucho mas intemporal.

Lo que sí ha cambiado, en forma radical, es el entorno y la diversidad que muestran las otras funciones en la educación superior a través de expresiones organizacionales concretas (universidades de diverso carácter: de investigación, ciberuniversidad, universidad-empresa, etc.). Cualquiera de ellas se enfrenta a realidades contingentes, tanto internas como externas, por lo tanto, el marco por medio del cual se aprecian sus atributos y se califica hoy su calidad y adaptación cambia dependiendo del código con el cual se evalúen sus funciones.

Por ejemplo, hasta hace pocos años, las distinciones sobre lo que debía enseñarse y cómo hacerlo era casi exclusivamente observado y definido desde dentro del sistema universitario. Los avances que reconocen los actores resultan estimulantes, pero conviven con carencias profundas y desigualmente distribuidas en el sistema, que filtran las opiniones de docentes y estudiantes y que son cruciales para dimensionar y consolidar los procesos de aseguramiento de la calidad, certificación en entornos cambiantes y diferenciados en ofertas públicas y privadas, en instituciones que alcanzan la acreditación de sus procesos o por el contrarios son rechazados.

Ello no sólo implicará incrementar las inversiones en plataformas tecnológicas y centros especializados en diseño y apoyo, sino que, sobre todo, involucrará abordar sistemáticamente las falencias de capacitación del profesorado, que no ha logrado transitar hacia una integración efectiva de los procesos de enseñanza-aprendizaje con los recursos de última generación. Para ser justos, sin embargo, es necesario recordar que en el contexto nacional de la educación superior privada se está lejos de disponer las asistencias técnicas 
adecuadas que requieren las modalidades telemáticas, o de ofrecer condiciones favorables en las jornadas docentes para perfeccionar el desarrollo de las nuevas modalidades de enseñanza que exigen las TIC. Otro aspecto relevante, dice relación con el hecho que un porcentaje importante de los docentes del sector privado no expresan el perfil cásico del profesor del sistema público, es decir, muchos de ellos sólo prestan servicios parciales y se desempeñan principalmente en el sector privado, no siguen la trayectoria de perfeccionamiento típica del pregrado al doctorado, no siempre forman parte de equipos y redes de investigación académica o no suelen publicar y participar con regularidad en reuniones científicas, como parte del quehacer habitual.

Por último, es necesario conocer la situación en el resto del sistema universitario chileno tanto público como privado y su diversidad regional así como latinoamericana y, sobre esa autorreferencia de conocimiento, construir estrategias que permitan no sólo incrementar la interrelación universidad/sociedad, sino que, a la vez, posibiliten nuevos impulsos para el desarrollo de las actividades definitorias de la identidad universitaria relativas a la creación, conservación y transmisión del conocimiento, así como la habilitación profesional de las nuevas generaciones, en una sociedad y momento histórico que se niega a abandonar las distinciones forjadas en épocas medievales y preindustriales, pero que resultan inadecuadas para enfrentar la actual complejidad y desafíos futuros.

\section{Referencias}

Area, Manuel. (2005). Las tecnologías de la información y comunicación en el sistema escolar: Una revisión de las líneas de investigación. Relieve, Revista Electrónica de Investigación y Evaluación Educativa, 11(1). Recuperado de http://www.uv.es/RELIEVE/v11n1/RELIEVEv11n1 1.htm

Area, Manuel. (2008). Una breve historia de las políticas de incorporación de las tecnologías digitales en España. Quaderns digitals, Revista de Nuevas Tecnologías y Sociedad, (51). Recuperado de http://www.quadernsdigitals.net/index.php?accionMenu=hemeroteca.VisualizaArticulol U.visualiza\&articulo id $=10454$

Bergero, Iris y Esnaola, Graciela. (2006). Nuevos retos para la formación universitaria de los comunicadores: ¿Cómo se construye el aprendizaje mediado por las TICs?. Revista Iberoamericana de Educación, (39), 1-5.

Bricall, Josep. (1998). Participación de la sociedad en las universidades. En Jaume Porta y Manuel Lladonosa (coords.), La Universidad en el Cambio de Siglo (pp. 195-216). Madrid: Alianza. 
Bricall, Josep. (2000). Calidad y Acreditación. En Informe Universidad 2000. Conferencias de Rectores de las Universidades Españolas, Barcelona: CRUE.

Brunner, José, Joaquín. (2008). El Proceso de Bolonia en el horizonte latinoamericano: límites y posibilidades. Revista de Educación, Ministerio de Educación y Ciencia, Número Especial, 119-145.

Brunner, José, Joaquín y Uribe, Daniel. (2007). Mercados Universitarios: El Nuevo Escenario de la Educación Superior. Santiago: Universidad Diego Portales.

Buendía, Leonor. (2003). Hacia una universidad de calidad: algunos problemas pendientes. Revista Educatio, Siglo XXI, (20-21).

Bueno, Eduardo. (2007). La tercera misión de la universidad: el reto de la transferencia del conocimiento. Revista de investigación en gestión de la innovación y la tecnología, (4). Recuperado de http://www.madrimasd.org/revista/revista41/tribuna/tribuna2.asp

Cantero, Alberto. (1999). Adecuación de la Universidad al Proceso de Globalización. En Jorge Brovetto y Miguel Rojas (eds.) Universidad Iberoamericana, Globalización e Identidad. Madrid: CEXESI.

Cantero, Carlos (ed.) (2003). Sociedad de la Información. Santiago: Universidad Tecnológica Metropolitana.

Castells, Manuel. (1997). La Era de la Información: Economía, sociedad y Cultura. Madrid: Alianza.

Castells, Manuel. (2005). Globalización, Desarrollo y Democracia: Chile en el Contexto Mundial. Santiago: Fondo de Cultura Económica.

De Luxan, José María. (1998). Política y Reforma Universitaria. Barcelona: Cedecs.

Donoso, Roberto. (1999). Mito y Educación. Impacto de la Globalización en la Educación en Latinoamérica. Buenos Aires: Espacio.

Etzkowitz, Henry. (2000). The future of the and the university of the future: evolution of ivory tower to entrepreneurial. Research policy, 29(2), 313-330.

Fernández, Enrique. (2009). Perspectivas de futuro de las universidades privadas fundadas con posterioridad a 1980. En José Joaquín Brunner y Carlos Peña (eds.), Reforma de la Educación Superior. Santiago: Universidad Diego Portales.

Ferraté, Gabriel. (1998). Universidad y nuevas tecnologías: El camino hacia la hiperuniversidad. En Jaume Porta y Manuel Lladonosa (coords.), La Universidad en el Cambio de Siglo (pp. 173-194). Madrid: Ed. Alianza. 
Flecha, Ramón y Tortajada, Lolanda. (2002). Retos y salidas educativas en la entrada del siglo. En Francesc Imbernón (Coord.), La Educación en el Siglo XXI. Los retos del futuro inmediato (pp. 13-27). Barcelona: Biblioteca Aula.

Gimeno, José. (2002). La Educación que tenemos, la educación que queremos. En Francesc Imbernón (Coord.) La Educación en el Siglo XXI. Los retos del futuro inmediato (pp. 29-52). Barcelona: Biblioteca Aula.

Hernández, Roberto, Fernández, Carlos y Baptista, Pilar. (2003). Metodología de la Investigación. México: Mc Graw-Hill.

Imbernón, Francesc (coord.) (2002). La Educación en el Siglo XXI. Los retos del futuro inmediato. Barcelona: Ed. Graó.

Lapiedra, Ramón. (1998). Planes de estudio, formación y necesidades sociales. En Jaume Porta y Manuel Lladonosa (coords.), La Universidad en el Cambio de Siglo (pp.103120) Madrid: Alianza.

Larraín, Jorge. (2005). ¿América Latina Moderna?, Globalización e Identidad. Santiago: LOM.

Luhmann, Niklas. (1996). Teoría de la Sociedad y Pedagogía. Barcelona: Paidós.

Monckeberg, María O. (2007). El negocio de las universidades en Chile. Santiago: Debate.

Mora, Arturo. (2006). Impacto de los procesos de acreditación en la Universidad de Concepción. Revista Calidad en la Educación, (24), 185-196.

Mora, José. y Fernández Norberto (coords.) (2005). Educación Superior, Convergencia entre América Latina y Europa. Procesos de Evaluación y Acreditación de la Calidad. Proyecto ALFA-ACRO, Buenos Aires: Universidad Nacional Tres de Febrero.

Perinat, Adolfo. (2004). Conocimiento y Educación Superior, Nuevos Horizontes para la Universidad del Siglo XXI. Barcelona: Paidós.

PNUD. (1998). Informe de Desarrollo Humano, Las Paradojas de la Modernización. Santiago: Programa de Naciones Unidas para el Desarrollo.

Porta Jaume y Lladonosa Manuel (coords.). (1998). La Universidad en el Cambio de Siglo. Madrid: Alianza.

Riveros, Luis. (2002). Mis visiones sobre Educación. Propuestas para un Debate. Santiago: Editorial Universitaria. 
Rodríguez, Emilio. (2009). Información y aseguramiento de la calidad de la educación superior. En José Joaquín Brunner y Carlos Peña (eds.), Reforma de la Educación Superior. Santiago: Universidad Diego Portales.

Rodríguez, Roberto. (2003). Educación Superior en el Mercado, Configuraciones emergentes y nuevos actores. En Marcela Mollis (comp.), Las Universidades en América Latina: ¿Reformadas o Alteradas? (pp. 87-107). Buenos Aires: CLACSO.

Rojas, Miguel. (1999). La función intelectual de la Universidad: ¿una responsabilidad abandonada? En Jorge Brovetto y Miguel Rojas (eds.), Universidad Iberoamericana, Globalización e Identidad. Madrid: Ed. CEXESI.

Salinas, Jesús. (2000). La integración de las TIC en las instituciones de educación superior como proyectos de innovación educativa. Universidad de las Islas Baleares. Recuperado de. http://www.uninorte.eu.co/congresog10/conf/06-laIntegración-de-las-TIC-en-las-Instituciones.pdf

San Martin, Patricia. (2005). Hipertexto. Seis propuestas para este milenio. Buenos Aires: La Crujía.

Tironi, Eduardo et ál. (2003). Cuánto y Cómo Cambiamos los Chilenos, Balance de una Década. Santiago: Instituto Nacional de Estadísticas.

Zabalza, Miguel. (2002). La Enseñanza Universitaria. El escenario y sus protagonistas. Madrid: Narcea Editores. 